\title{
Effect of Online Classes on Working Mothers
}

\author{
Merlin Flavy Dsouza ${ }^{1}$, Lochana Bopanna $C^{2}$, Devika N T ${ }^{3}$, Lenisha Noronha ${ }^{4}$, \\ Angel Maria Phillip 5
}

\author{
UG- Bachelor of Arts, St. Agnes College (Autonomous), Mangalore, Karnataka ${ }^{1-5}$
}

\begin{abstract}
The corona pandemic had a major impact on a person's mental and physical health. Women, particularly working mothers who had to juggle between the work at home and also the work at the workplace along with their children's classes, suffered from serious physical and mental health problems. Due to the increase in Covid-19, and the implementation of lockdown, there was a higher risk of mental health problems. Women mostly suffered from loss of job, loss of loved ones, fear of the virus and pandemic, domestic violence and loneliness. Along with these problems there was an additional responsibility of their child's online or pre- recorded classes.
\end{abstract}

We intended to conduct a survey and research about how online classes had effected the working mother's mental health and physical health. The questionnaire has 30 questions which includes personal data, questions related to mental and physical health problems. The sample consists data of 50 working mothers.

The hypothesis of the study is that, the working mothers would experience greater level of problems with their children's online classes than before. This may be because of extra work they that they had to perform along with their professional work.

Keywords:- Online classes, Pre- recorded classes, working mothers, covid-19, Mental health, Physical health, Lockdown.

\section{INTRODUCTION}

The Covid-19 pandemic has severely disturbed the education system and also forced the schools and colleges to have a hurried shift to virtual learning. Online classes have become an important element of today's educational system and they have gotten even more significant, as a result of Covid-19 pandemic. Online education is a virtual form of learning which is delivered and administered through the use of internet. With the lockdown situation, as a result of Covid-19, academic activities of every educational institution came to a halt and the adverse effect of the same is widely visible among the learners. Fortunately, with the advancement of technology, the scope for creating the virtual classroom was successful, thus making the online learning successful some extent for both the teachers and students.

The term e-learning was first used in a seminar on Cognitive Behavioral Therapy systems. Other terms, such as 'online learning' and 'virtual learning', began to emerge later on. Online learning is a type of learning that is based on institutionalized instruction but uses electronic resources.

India employs 397 million people, 123 million of whom are women. There are 106 million in rural areas and 18 million in urban areas. Only $20 \%$ of women laborers are employed in urban areas. Working mothers are women who are mothers who work outside the home to supplement their income in addition to parenting their children at home.

In this steadfast life, managing a holistic lifestyle can lead to stress and fatigue. The Covid-19 pandemic had a significant impact on all the working mothers who had to combine job, family responsibilities, and their children's schooling, which could also be due to the bereavement, isolation, loss of income. Fear of the pandemic can trigger or exacerbate mental health problem. According to a source, more than $83 \%$ of the working women reported that they suffered from depression in February 2021, meanwhile, anxiety has reached over 52\% since February.

Women have additional barriers and challenges in the workforce along with the childcare. The lockdown had put up tons of stress on parents, especially working mothers of India. When schools were closed and the classes were conducted through the online mode, which required active guidance from parents especially mothers, added additional burden on working mothers. Some women have also suffered from migraine,sleep disorder persistent exhaustion and difficulty of concentration. 


\section{International Advanced Research Journal in Science, Engineering and Technology \\ Impact Factor $7.105 \div$ Vol. 9, Issue 1, January 2022 \\ DOI: $10.17148 /$ IARJSET.2022.9146}

Online classes had adverse effects on physical and mental health of the mothers. There was also a conflict between their work and kids. According to a study, virtual learning was harder for working mothers as well. There can be various factors which effect the mental heath of working mothers such as insufficient co-operation from the family members thus it becomes difficult for the working mothers to manage household and office duties due to stress caused by job loss or work pressure. There were also cases of household violence of women reported during the pandemic. Most of the mothers were always worried about their child's future which in turn effected the mental health of the mother. Some of the other problems faced by them are financial problem, reduced or no privacy and isolation.

Adjusting to the new normal during this period was not so easy for the working mothers, especially for a working woman who had to juggle between her career, home, and personal time which may result in stress and fatigue. Adding to the hurdles this world puts up in front of you for being a woman, and it is enough to fester depression or anxiety.

\section{METHODOLOGY}

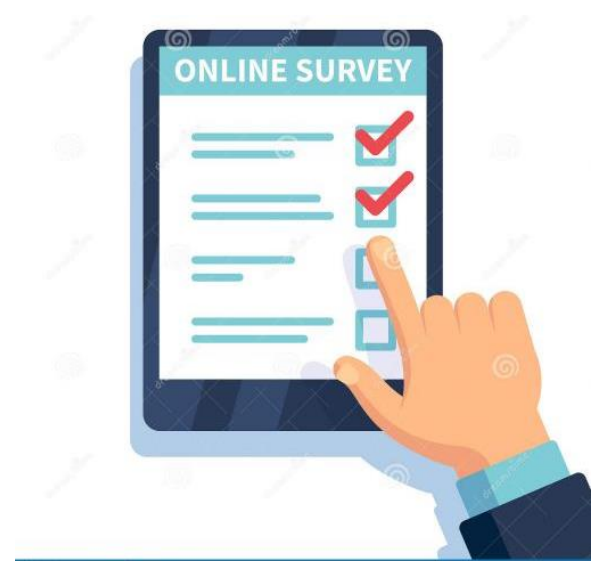

Fig. 1 Online Survey on effects of online classes on working mothers

An online questionnaire survey was used to collect the primary data on the effect of online classes on working mothers. The questionnaire has 30 questions, including personal data and inquiries on physical and mental health issues. The survey was given to 50 working women to find out what issues they had with their children's online classes

\section{RESULTS AND DISCUSSION}

The survey was administered to 50 working mothers aged between 30-55 with children who are between 4-21 year age group.

\section{Did your child have?}

\section{0 responses}

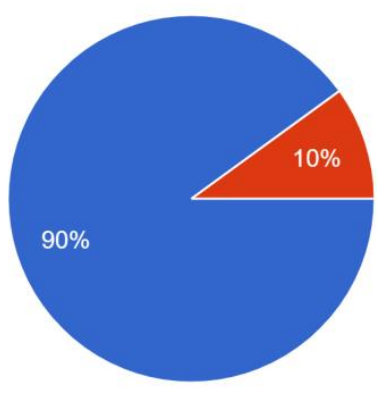

Live online classes

Pre-recorded classes

Fig.2 Live online classes V/s Pre- recorded classes 


\section{International Advanced Research Journal in Science, Engineering and Technology \\ Impact Factor $7.105 \div$ Vol. 9, Issue 1, January 2022 \\ DOI: $10.17148 /$ IARJSET.2022.9146}

During our survey it was found that, $90 \%$ of the students were engaged in online classes, whereas the rest $10 \%$ had prerecorded classes. Most of the children had classes for about 3-4 hours a day. According to the result, $42 \%$ of the children were assisted by his/her mother and $42 \%$ of the children helped themselves with the classes. Most of the mothers felt that their child was not so attentive(68\%) during the online classes. 25 out of 50 working mothers were able to adopt to this new, online mode of learning.

Since there was wide spread lockdown all over the country, with all the family members at home, the mother had to spend most of her time in the kitchen. $66 \%$ of the results prove this statement. 27 out of the 50 working mothers reported that their spouse sometimes helped them to complete the household chores. Around 64\% of the participants felt that they sometimes had time for themselves after completing all of their household and professional work.

As per our study, the mother's did not feel the need to take leave from their professional work for the sake of the child's online class. However, 20 working mothers had to take leave sometimes and 5 mothers had to always take leave from their job to meet the child's educational needs.

About 28 of the participants noticed there was a drastic changes in their relationship (56\%) with the child. $8 \%$ of the mothers felt that their child never informed them about the difficulties faced and only sometimes(54\%) the child discussed about the difficulties. Some of the difficulties faced by the children were increased level in stress, headache, eye soreness, obesity, loneliness, lack of social interaction and motivation. During this period, the majority of mothers struggled to meet their children's needs.

Did online class have effect on your physical health?

50 responses

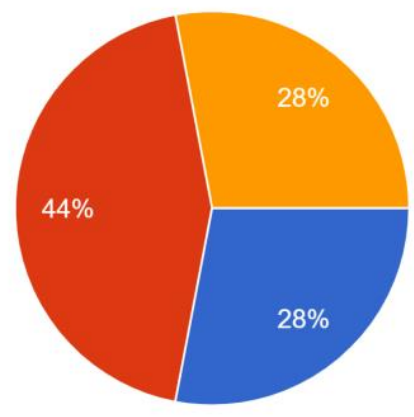

Always

Sometimes

Never

Fig.3 Effect of online classes on Physical health of working mothers

\begin{tabular}{|l|c|c|c|}
\hline $\begin{array}{l}\text { PHYSICAL HEALTH PROBLEM FACED } \\
\text { BY THE WORKING MOTHERS }\end{array}$ & ALWAYS & SOMETIMES & NEVER \\
\hline HEADACHE & 07 & 29 & 14 \\
\hline MUSCLE CRAMP & 06 & 17 & 27 \\
\hline OVER WORK & 06 & 33 & 14 \\
\hline
\end{tabular}

Table 1. Physical health problems faced by working mothers

The above table and chart shows the effect of online class on the physical health of the working mothers. According to the findings, $44 \%$ of the participants occasionally had problems with their physical health, $28 \%$ had always and $28 \%$ never had problems with their physical health. Working mothers often complained about headache and migraine, stomachache, eye sight problem, muscle cramps which affected their work efficiency. 
International Advanced Research Journal in Science, Engineering and Technology

Impact Factor $7.105 \div$ Vol. 9, Issue 1, January 2022

DOI: 10.17148/IARJSET.2022.9146

Did online classes effect your mental health?

50 responses

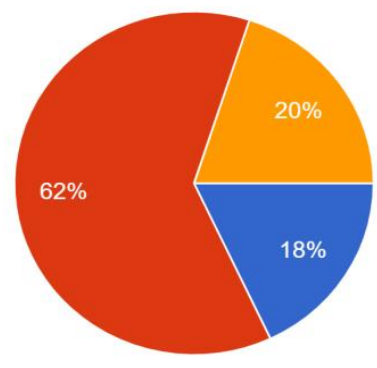

Fig.4 Effect of online classes on mental health of working mothers

\begin{tabular}{|l|l|l|l|}
\hline $\begin{array}{l}\text { MENTAL HEALTH PROBLEMS FACED } \\
\text { BY THE WORKING MOTHERS }\end{array}$ & ALWAYS & SOMETIMES & NEVER \\
\hline DEPRESSION & 06 & 23 & 21 \\
\hline STRESS & 10 & 29 & 11 \\
\hline PANIC & 02 & 37 & 11 \\
\hline IRRITABLE & 07 & 39 & 04 \\
\hline PATIENCE & 11 & 38 & 01 \\
\hline WORRIED & 17 & 32 & 01 \\
\hline ANXIETY & 08 & 34 & 08 \\
\hline
\end{tabular}

Table 2. Mental Health problems faced by working mothers

31 out of the $50(62 \%)$ working mothers reported that they sometimes experienced mental health issues during the pandemic because of their child's online classes. Among the various mental health problems, the survey found out that, stress $(58 \%)$, anxiety $(68 \%)$, depression(46\%), panic(74\%), irritability(78\%) were more common. $22 \%$ of the working mothers had reduced level of patience due to the stress that they faced during the Covid-19.

The mothers felt that the online classes were not that effective compared to the offline classes because of the inattentiveness of the child, lack of interaction between the teacher and the student. Since there wasn't any practical classes, which made the parent worry about the child's future due to the online classes and the impact it had on the mental and physical health of the child.

\section{CONCLUSION}

On the whole we can conclude that, some of the mothers faced difficulty while maintaining a balance between her work life and personal life. Most of the mothers were not satisfied with the online mode of learning and preferred to have blended learning i.e combination of both online classes and offline classes.

\section{REFERENCES}

1. Dr. P. Bharathi, Dr. T. Vijayakumar. "Online Classes and Working Mothers Conception as Educators: an Expository Study”, NVEO, Volume 8, Issue 4, 2021.

2. Christine A. Limbers, Christina McCollum, Emma Greenwood. "Physical activity moderates the association between parenting stress and quality of life in working mothers during the COVID-19 pandemic", Mental Health and Physical Activity

Volume 19, 100358, October 2020.

3. Jayita Poduval, Murali Poduval. "Working Mothers: How Much Working, How Much Mothers, And Where Is The Womanhood?” Mens Sana Monogr, 7(1): 63-79. doi: 10.4103/0973-1229.41799, 2009 Jan-Dec.

4. Ankita Verma. "Working Women and Motherhood -A Review", Annals of Biology, January 2020.

5. "Impacts of lockdown on the mental health of children and young people", Mental Health Foundation. 


\section{International Advanced Research Journal in Science, Engineering and Technology \\ Impact Factor 7.105 다. 9, Issue 1, January 2022 \\ DOI: $10.17148 /$ IARJSET.2022.9146}

6. Shweta Singh, Deblina Roy, Kritika Sinha, Sheeba Parveen, Ginni Sharma, Gunjan Joshi. "Impact of COVOD-19 and lockdown on mental health of children and adolescents: A narrative review with recommendations", Psychiatry Res, 293: 113429, November 2020.

7. Usha Ranji, Brittni Frederiksen, Alina Salganicoff, Michelle Long. "Women, Work, and Family during COVID-19: Findings from the KFF Women's Health Survey”, March 22,2021.

8. Jess Huang, Alexis Krivkovich, Ishanaa Rambachan, Lareina Yee. "For mothers in the workplace, a year (and counting) like no other', McKinsey \& Company, may 5, 2021.

9. Matt Zalaznick. “How online learning affects parents' mental health”, District Administration, December 16, 2020.

10. CBS Mornings. "Families face challenges with online learning during coronavirus crisis”, March 17, 2020.

11. https://www.questionpro.com/blog/distance-learning-survey-for-parents $\wedge$

12. Vartika Kapoor, Jaya Yadav, Lata Bajapai, Shalini Srivatsava. "Perceived stress and psychological well-being of working mothers during COVID-19: a mediated moderated roles of teleworking and resilience" Employee Relations Journal, ISSN: 0142-5455, April2, 2021.

13. Marco Tommasi, Francesa Toro, Simone Arno, Angelo Carrieri, Marco Maria Conte, Marianna Daria Devastato Laura Picconi, Maria RitaSergi, Aristide Saggino. " Physical and Psychological Impact of the Phase One Lockdown for COVID-19 on Italians”, Frontiers in Psychology, December 17, 2020.

14. Mengting Wu, Wenyan Xu, Yuhong Yao, Lei Zhang, Lei Guo, Juan Fan,and Jue Chen, "Mental health status of students' parents during COVID-19 pandemic and its influence factors, July 21, 2020.

15. Juliann Garey. "Single Parenting During the Coronavirus Crisis", Child Mind Institute.

16. Lori Uildriks. "Pandemic measures had a strong impact on mental and physical health", Medical News Today, October 27, 2020.

17. Shruti Kharbanda. "Struggles of a working mother with online classes", Cityspidey, February 21, 2021.

18. Aiswarya Ramasundaram. "The working mother, a winner all the way", The Hindu, August 14, 2011. 